\title{
US-Mexico Border: Building a Smarter Wall through Strategic Security Measure Allocation
}

\author{
Taylor Leonard \\ Georgia Institute of Technology \\ Eva K. Lee \\ Georgia Institute of Technology
}

We offer a quantitative construct for optimizing security measure investments, to achieve the most costeffective deterrence and detection capabilities for the U.S. Customs and Border Patrol (CBP). We constructed a large-scale multiple-objective portfolio optimization integer program that rapidly returns good Pareto optimal results. The model incorporates the utility of each measure and the probability of success, along with multiple other objectives. To the best of our knowledge, our work presents the first mathematical model that optimizes security strategies for the CBP and is the first to introduce a utility factor to emphasize deterrence and detection impact. The model accommodates different resources, constraints, and various types of objectives. The solution methodologies being put in place are complex, current state-of-the-art, and very effective.

\section{INTRODUCTION}

The large influx of immigrants across the US-Mexico border has seriously strained the US Government's capacity to handle border safety and protection. The situation is further aggravated with thousands of immigrant children separated from their parents or family members and being held at Border Patrol facilities. Although there have been numerous debates regarding strategies and policies in securing border safety and in mitigating the risks and danger migrants go through to arrive at the United States seeking a better future, an effective unifying theme of border security and operational infrastructure has not emerged.

Immigration and security along the southern border have long been a well-publicized topic of debate and dissension. We acknowledge that there are social and humanitarian issues present in this area of research, and we are exploring some of these in additional research papers. We, the authors, do care about illegal immigrants and their physical and social well-being, but this is not a political paper. This paper is focused on constructing a mathematical model that aids the government in how they spend their budget on selecting resources for the U.S. operational security infrastructure. The simple fact is the U.S. does have a southern border where hundreds of thousands of immigrants attempt to enter the country illegally. The proposition most favored politically at this time is to construct additional wall segments and update existing structures along the border. This paper presents a mathematical model that will assist the U.S. Customs and Border Protection (CBP) in determining whether the wall is a prudent investment to the 
safety and security of all people involved or if there are other security investments that can aid more in detection and in non-physical deterrence.

There is much academic research that describes security between ports of entry, but almost none of this research is mathematical in nature. Mostly, the existing research focuses on leveraging, as the prime mechanism of deterrence, the mortal danger the migrants face in navigating remote wilderness locations. This leveraging was an explicit part of Border Patrol's deterrence-based strategic planning. In large part, what brought greatest academic attention to a deterrence-driven border policy was that the ratio of deaths to CBP migrant apprehensions skyrocketed and had been steadily increasing into the latter $2010 \mathrm{~s}$, even as projected migration rates declined (Chambers, 2019). The misconception with non-mathematical usage and explanations of these numbers is that migrant deaths have been increasing for years across the border. The truth is the annual number of deaths is approximately $21 \%$ lower than the 20 -year average, $26.5 \%$ lower than the number of death 10 years ago, and $7.6 \%$ higher than the number of deaths 20 years ago (U.S. Border Patrol Southwest Border Deaths by Fiscal Year, 2019). The drastic difference/increase in the ratio of deaths to apprehensions is due to the $75 \%$ decrease in apprehensions in the last 18 years (U.S. Border Patrol Total Illegal Alien Apprehensions By Fiscal Year). It is correct that the number of deaths has increased in certain sectors due to the "Funnel Effect," or avoidance of increased border surveillance technology in other sectors, but the rates also drastically decreased in the monitored areas (Chambers, 2019). Overall, this tells us that deterrence-based strategic efforts are possibly contributing to the reduction in attempted illegal crossings.

There are arguments that deterrence based strategies increase injuries to immigrants. The literature actually presents the scenarios where immigrants attempt to cross the border over the large border fences and have injured themselves from falling off of them (Jusionyte, 2018). It is obvious in the results presented in this paper that spending additional funds on the wall is not the best solution and that there are other, more effective, and less physical methods that can deter immigrants. Obviously, any loss of life is tragic, but our mathematical model can be used to encourage funding of deterrence and detection methods, even in remote areas. Not only would this aid in decreasing migrant attempts in the dangerous routes, but it would also assist CBP agents and first responders in assisting those individuals that are injured in their crossing attempts. The US-Mexico border is approximately 1,933 miles long. As a result of the Secure Fence Act in 2006, hundreds of miles of physical fence were constructed along the border. Currently, 1,279 miles, $66 \%$ of the border is unfenced; the Rio Grande River makes up much of this unfenced border.

In the study, we present a vigorous systems modeling approach to analyze how best to establish effective border strategies in deterrence and detection through optimal security measures investment. 


\section{FIGURE 1 \\ U.S. MEXICO BORDER}

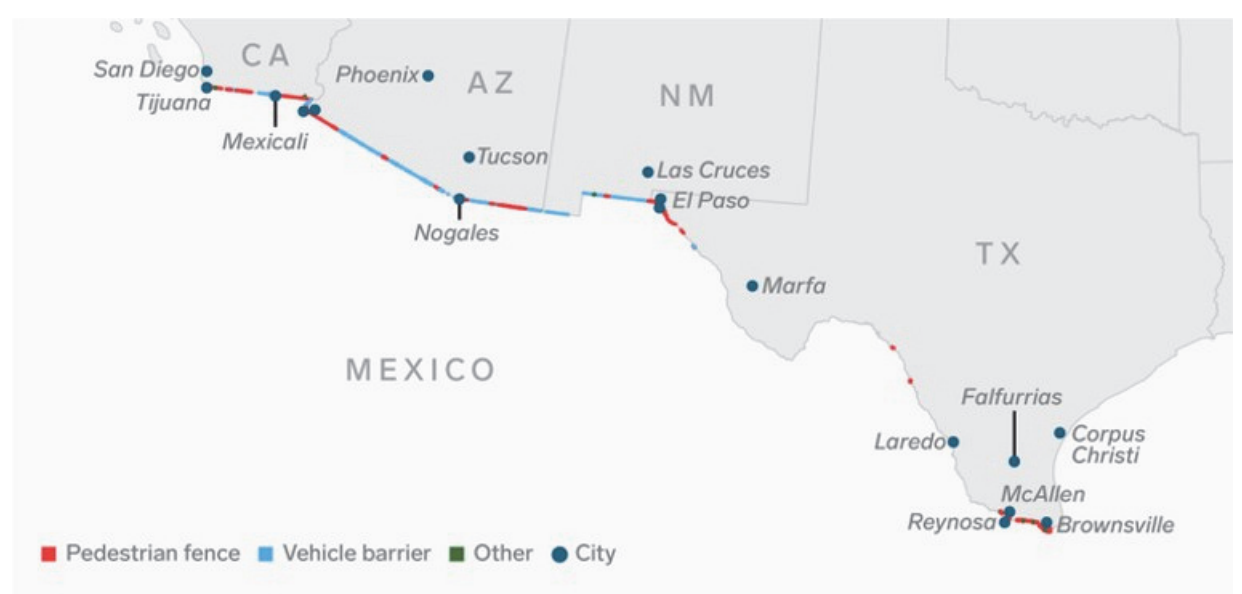

(Mark \& Kiersz, 2019)

Within the field of portfolio investment research, there is a serious gap in incorporating enterprise risk management (ERM) within the operational level. Recently, our team analyzed strategies for security measure allocation for optimal aviation security and designed a computational framework for multi-tier risk taxonomy modeling and strategic assessment (Leonard, Lee, Booker 2020, Lee, Leonard, Booker 2020). In this paper, we leverage this flexible, scalable modeling framework to tackle the borders, taking into account the full multi-tier enterprise risk management (strategic, tactical, and operational levels).

We model the U.S. Customs and Border Protection ERM in 3 tiers. Tier 3 consists of satellites monitoring the geographic area of the border. This allows for $24 / 7$ surveillance and data gathering, pinpointing high-frequency crossing areas, and addressing vulnerable locations. Tier 2 employs High Altitude Long Endurance (HALE) drones with high fuel capacity for extended surveillance. They provide higher resolution images compared to Tier 3 and are equipped with infrared capabilities to find hidden smuggling camps, etc. Tier 1 is the ground layer, which includes a variety of security surveillance systems and manned outposts. This operational layer is equipped with quadcopter drones, intermittent outposts along the border, and sensor technology in between. The outposts serve as command posts for drone swarms and also as home bases for analyzing information streams from all tiers. The sensors can identify border crossings as well as attempted tampering with existing wall structures and the ground below. Swarms of drones can be sent out as quick response teams to identify crossers better or interdict them. 
FIGURE 2

A THREE TIER SECURITY CAPABILITY ARCHITECTURE

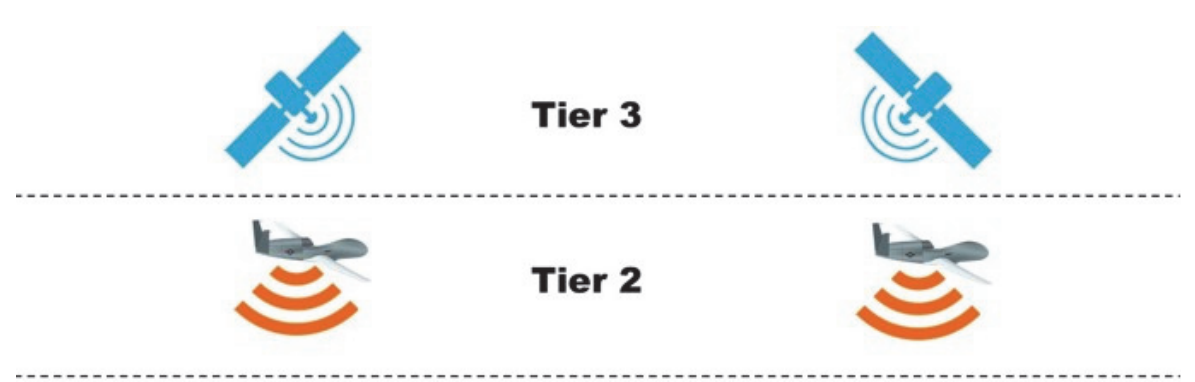

Tier 1
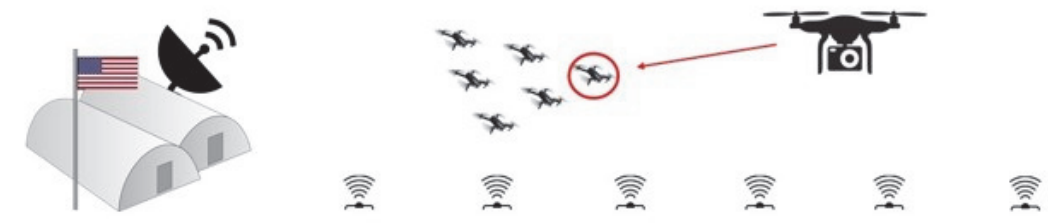

CBP has made positive strides in protecting the border. However, multiple challenges remain. A critical element is to utilize the border agents' time more efficiently and effectively. The number of CBP agents has grown several times over in the past two decades, but the quantity of manpower is never quite enough. The requirements that a physical agent be present for identification, verification, or detection are continuously straining the manpower resources. Some of this pressure can be alleviated by employing "smart" security measures. For example, false alarms could be identified by drones or surveillance equipment. Risk levels and priority scores can be dynamically generated to better allocate different resources on a day to day basis with real-time information coming from the "Smart Wall." With the use of surveillance technologies and drones, illegal immigrants can be deterred from illegal crossings nonviolently. Drones play a big part in surveillance, but can also be used to scare away potential smugglers. The loud sound of the rotors and drones flying low-overhead as well as noise emitting technology could be used to scatter or deter groups of smugglers. Detecting "unseen" threats are much easier with the use of advanced technology. Tunneling has become a common smuggling method and can go undetected until actual contraband reaches the other side of the border. With smart, highly sensitive sensors, the consistent vibrations of digging could be detected and separated from the interference (such as animals) using pattern detection technology. Agents can be alerted in real-time, allowing for preemptive security. 24/7 information flow allows agents to monitor and learn smugglers' patterns. It may even be possible to learn the patterns of smugglers/smuggling (favorite combinations of routes, time of day, weather, etc.) through machine learning to be steps ahead.

\section{REQUIREMENTS ANALYSIS}

In determining requirements, Tier 3 is omitted and assumes satellite systems are already in place. Tier 2 includes military-grade surveillance technology. For example, the cost of acquisition of HALE drones, such as the MQ-4C Triton, is roughly $\$ 120$ million each. Tier 1 requirement includes commercial drones. Commercial drone technology is developing at a rapid rate, and top of the line is constantly changing. We use the DJI Mavic Air as the base drone for our analysis. This drone has an effective range of 6.2 miles and costs $\$ 800$ each. With a border length of $\sim 1,934$ miles and an effective drone mission range of 6.2 miles, an outpost to act as the command center for these drones will need to be placed approximately every 12.4 miles to ensure $100 \%$ coverage. This leads to approximately 162 outposts along the border, which would need to be staffed accordingly. Unattended ground sensors would be located between 
outposts and would send alerts when suspected crossing or border tampering such as digging under existing barriers occurs.

CBP's primary objective is border security. There are over 60,000 employees, a third of whom are border patrol agents. The southern continental border includes the border states of California, Arizona, New Mexico, and Texas. The border is split into nine "sectors," which are divided into 74 "stations," with each containing specific patrol zones. In the current state, CBP only has effective (physical) control of 680 miles of the border, while the Rio Grande River serves as a natural barrier of over 1,000 miles. (S\&T Impact: Borders \& Ports of Entry)

\section{FIGURE 3 \\ MAP OF THE NINE BORDER SECTORS ALONG THE US-MEXICO BORDER (OFFICE OF THE INSPECTOR GENERAL $\left.{ }^{(1)}(2017)\right)$}

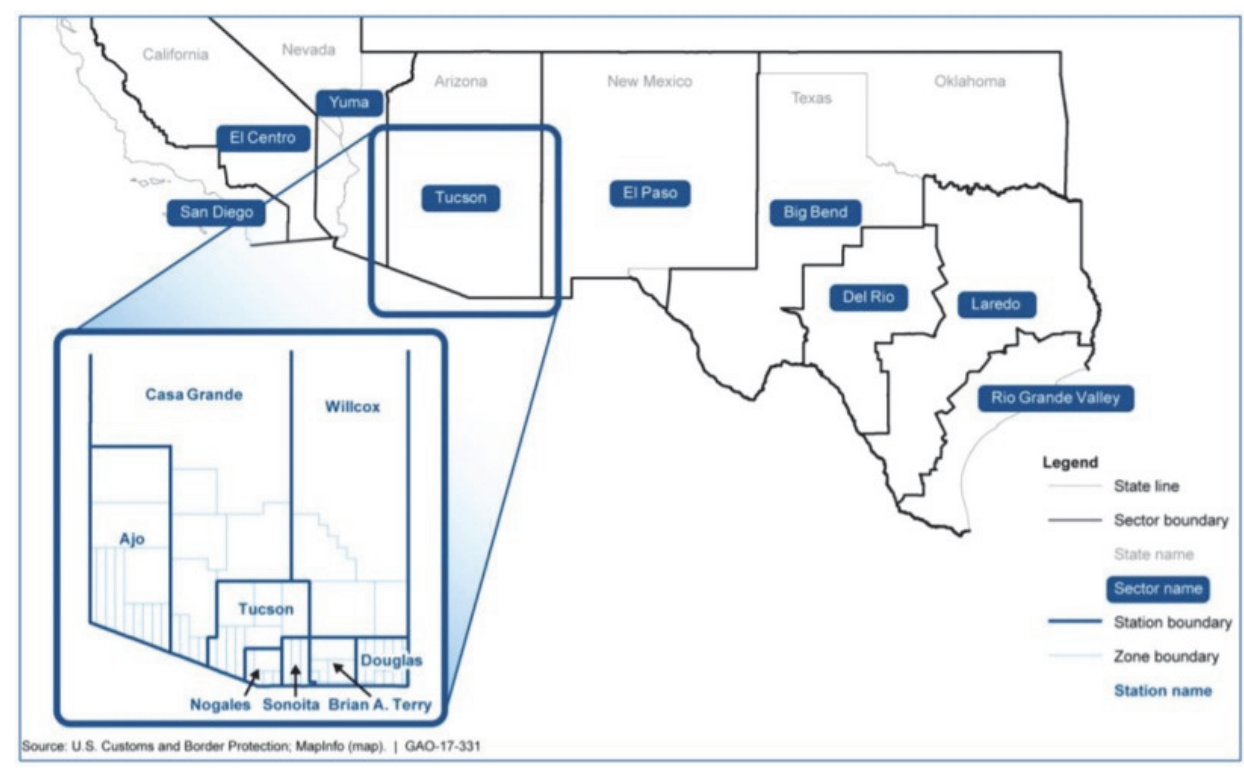

CBP annually collects data from frontline border patrol agents and chiefs from each of the nine patrol sectors along the Southwest border. There are roughly 500,000 illegal entries per year. The data collected identifies vulnerabilities, or "capability gaps." CBP then catalogs preliminary requests for solutions to address capability gaps that include infrastructure, technology, personnel, etc. The CBP Wall Decision Support Tool (WDST) identifies the relative priority of various segments along the border for the proposed border wall. The inputs are based on the feedback from the sector chiefs. (Committee of Homeland Security \& Governmental Affairs (2018))

Focusing on CBP's highest priority vulnerabilities across all capability gaps (902 total), we observe the following key findings (Committee of Homeland Security \& Governmental Affairs (2018))

- Less than $0.5 \%$ of the proposed solutions from CBP agents and sector chiefs included a request for a "wall."

- Less than $4 \%$ of proposed solutions from CBP agents and sector chiefs included a request for additional "fencing."

- Only one "Urgent and Compelling" request (out of 14) mentioned either a wall or fencing.

- $25 \%$ of vulnerabilities can be addressed using the man-made infrastructure of any kind.

- The remaining 75\% indicate the needs for technology and personnel approaches to advance border security.

The report presents a uniform opinion of CBP personnel's desire to integrate technology along the entire border to advance and improve border security. The physical border wall does exist and has been in 
place for many years, with some areas being modernized in the last five to seven years. The cost of modernizing the remaining legacy fence is cost-prohibitive at an average of $\$ 5.494$ million per mile and would exhaust all available funds (Office of the Inspector General ${ }^{(1)}$, 2017). The remaining two-thirds of the open border contains terrain where technology is much more useful.

A modular multi-layered (tiered) system is desirable for achieving operational efficiency and strategic gains. Adding new technology and supplementing existing technology will facilitate this system's approach. New technology includes UAVs, tethered drones, unattended ground sensors, infrared detection, surveillance systems. They have generated a shift in security tactics that many believe can be very beneficial. (Office of the Inspector General, 2017)

In this study, we apply risk-based modeling to determine the most cost-effective security measure investments. The effectiveness is based on reducing the likelihood of attack (increasing detection and/or deterrence). Such models empower policymakers to make sound and informed decisions in allocating funds. (Lavender, 2017)

\section{EXISTING SECURITY MEASURES}

Geographically, approximately $90 \%$ of the primary border fencing on the SW border is in the five western-most sectors, with the remaining $10 \%$ of primary fencing located in the four eastern-most sectors where the majority of the border is delineated by the Rio Grande River.

\section{FIGURE 4}

\section{EXISTING US-MEXICO BORDER FENCING (OFFICE OF THE INSPECTOR $\left.\operatorname{GENERAL~}^{(1)}(2017)\right)$}

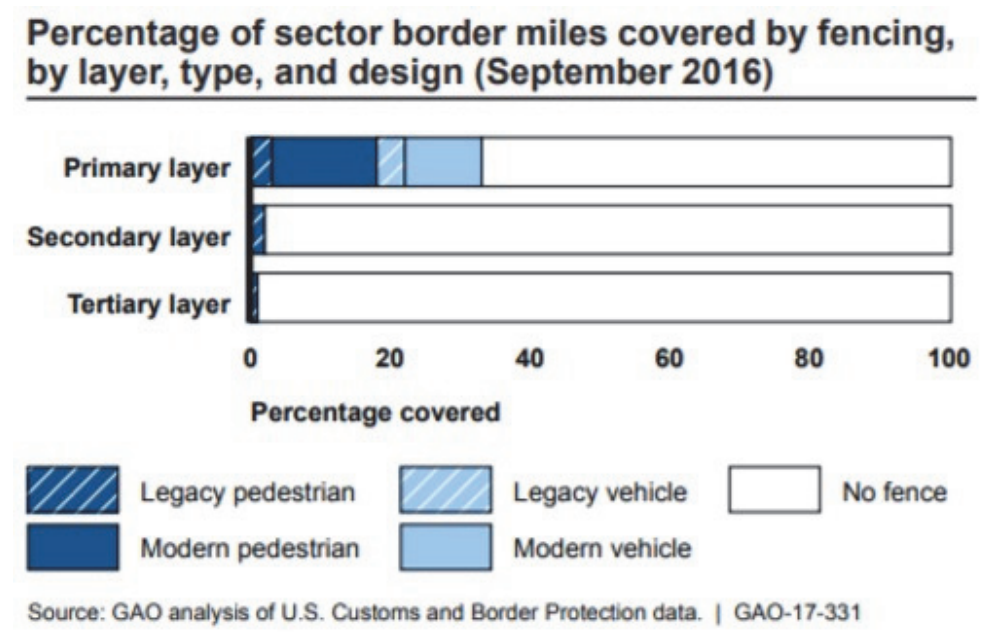

CBP employs a system of interconnected security layers to deter and detect illegal immigration and criminal activity. Table 1 summarizes a sample list of existing security measures and the estimated values across the 9 sectors. Some of these values are derived from existing documentation, while others are estimates based on public announcements of new installations (Office of the Inspector General ${ }^{(1)}(2017)$ ). Specifically, the physical and Tier 3 security measures are known quantities and locations. Tier 2 and Tier 1 security measures do exist. However, their exact values or locations are uncertain. We demonstrate the use of our system by inputting the Tier 3 measures and allowing the model to determine the initial purchase and assignment quantities across the sectors and stations. Other security measures include aircraft, UAVs, etc. with estimated values/locations/cost. 
The border surveillance systems are comprised of combinations of surveillance technologies that are designed or utilized to assist the CBP in enforcing U.S. laws and to detect, identify, apprehend, and remove persons and illegal contraband. Since the 2014 BSS assessment, CBP has deployed new technologies, including mobile, fixed, and other technologies. (Luck, 2018)

Mobile surveillance technology includes Tactical Aerostats (TAS), lightweight Counter-Mortar Radar/Lightweight Surveillance and Target Acquisition Radar (LCMR/LSTAR), and Man-Portable Aerial Radar System-Kits (MARS-K). (Luck, 2018). The TAS units are significant to the program and provide a low-cost, low-flying satellite system. The TAS units include wireless transmitters, are capable of detecting all aircraft within a 200-mile range, and all data is downloaded and integrated to the Air and Marine Operations Center (AMOC). (Long) The LSTAR radars provide 360 degrees 3D electronic scanning capabilities for detecting and tracking airborne targets. The LCMR systems provide continuous 3D 360-degree surveillance and 3D rocket, artillery, and mortar location using a non-rotating electronically steered antenna. Integrated Fixed Towers (IFTs) are integrated with the Tracking and Signcutting Modeling (TSM). The IFTs include day and night cameras, radar, and laser illuminator sensors that can be monitored from local sector facilities. (Luck, 2018). 


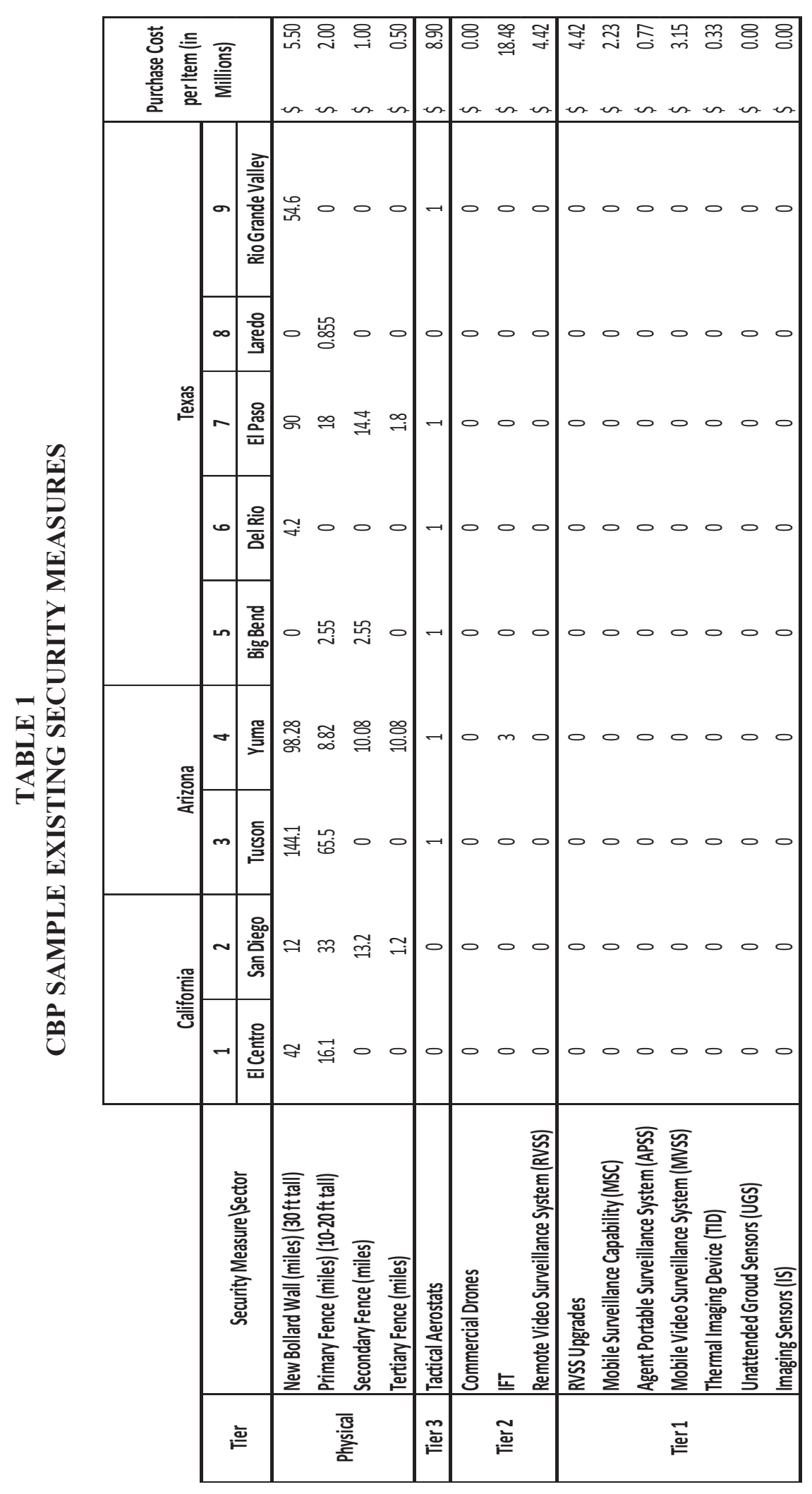


Other surveillance technology includes the cross-border tunnel threat (CBTT) program, the border tunnel activity detection system-point (BTADS-P), linear ground detection systems (LGDS), and unattended ground sensors (UGS). The CBTT program employs tunnel detection technology to enhance the tunnel activity monitoring capabilities. It is a network of subterranean ground sensors collecting seismic information that includes people walking near the border, climbing over fences, digging near the sensors, vehicles or animals near the border, and low flying aircraft. The BTADS-P, LGDS, and UGS are all different types of sensors used in the CBTT that are useful for detecting when a tunnel is actively being constructed or provide long-term physical intrusion detection. (U.S. Customs and Border Protection, 2015)

\section{LITERATURE REVIEW}

Little has been reported in the literature regarding the measures of effectiveness of existing border security. Simply looking at the number of apprehensions could be very misleading. A decrease in the number of apprehensions could indicate either successful border enforcement or failed border enforcement. Success could be due to rising deterrence and fewer attempts. Failure could be due to more successful illegal entries. Hence we greatly need some robust estimates of the likelihood that an unauthorized border crosser will be stopped and detained. Similarly, it is important to know what type of security measures are responsible for the identification of border crossers being apprehended. Our objective is to establish a combination of security measures by sector to increase the apprehension rate or deterrence rate.

The current state of enforcement is a work in progress. Arizona is the first state to experience technology upgrades at its border. The original upgrade plans called for 52 Integrated Fixed Towers, underground sensors, night vision scopes for trucks, and remote video surveillance systems.

This study establishes a mathematical model that supports border security and includes both physical and technological security measures. The model determines the best combination of security measures based on their detection characteristics and capability (and potentially other factors). Security measures can be tailored to each sector and an area of coverage based on the average number of apprehensions per month and physical attributes of each sector. This could be further tailored to specific station requirements. The apprehension rates used in the model (Table 2) are based on the FY18 statistics. The monthly average sector rates are used to determine the quantity of each security measure required to ensure $100 \%$ apprehension.

There is very little academic research about border security between immigration ports. Bristow provided the only model that analyzed the border wall in Arizona (Bristow, 2017). The model focuses on infrastructure on the Arizona border and how to decide to upgrade infrastructure based on current effectiveness levels. There is a serious lack of mathematical models developed to support border decisionmaking strategy. This is a timely opportunity to analyze resource allocation across all sectors holistically to maximize the global effectiveness. 


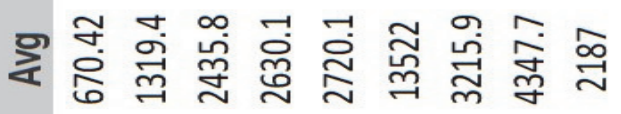

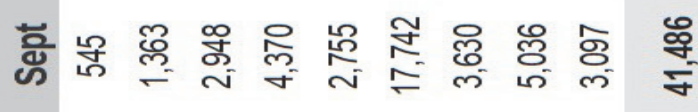

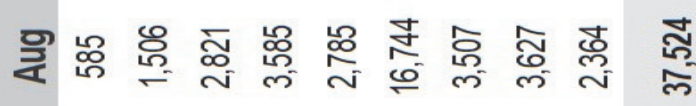

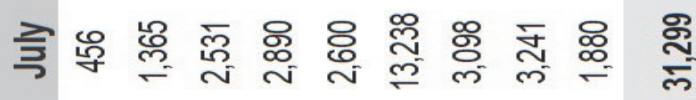

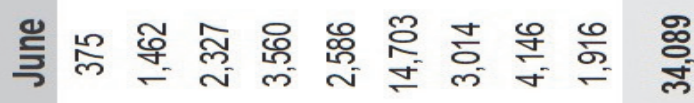

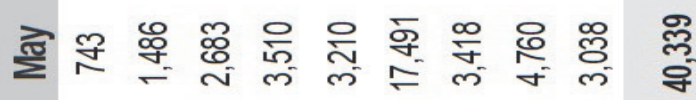

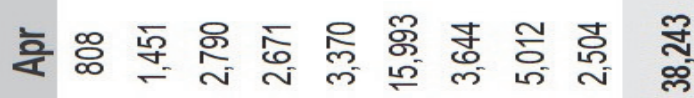

نำ

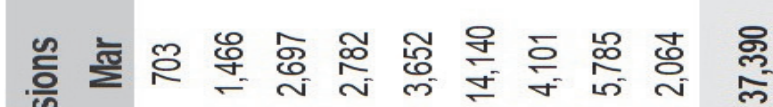

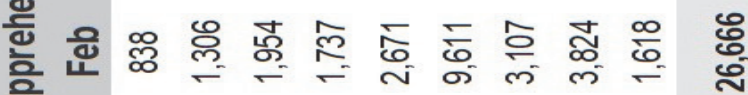

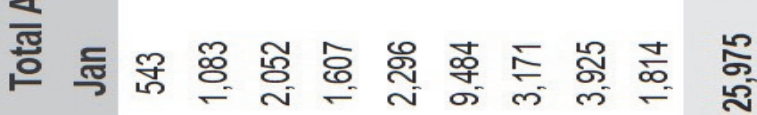

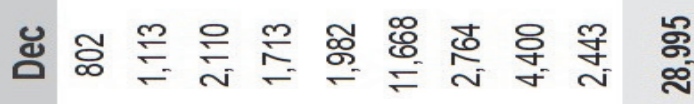

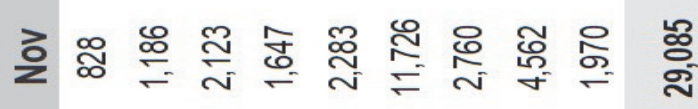

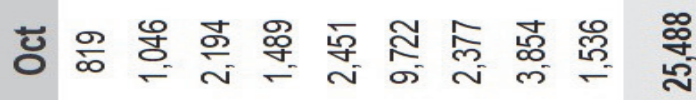

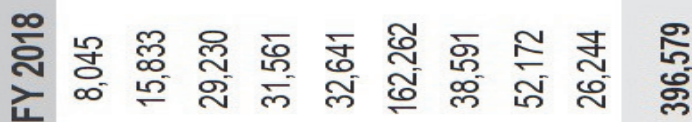

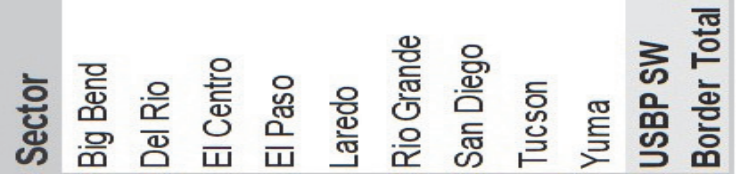


We leverage our recent multi-objective resource allocation model developed for TSA airport security analysis (Leonard, Lee, Booker, 2019). Specifically, we introduced a large-scale integration and expansion of the work by Nie et al. and Sewell et al. (Nie et al., 2009, Sewell et al., 2012, Sewell, et al., 2013). The systems TSA model determines an optimal allocation of threat detection devices and measures for screening checked baggage, carry-on baggage, and passengers across a set of airports so as to 1) maximize risk posture, 2) maximize the number of threats detected, and 3) minimize the overall false alarm rate while considering passenger threat classification. Constraints are imposed on the time available at each check station, flow capacity at security stations, budget, as well as staffing needs at each check station. We employ the TSA construct for the CBP border security model herein. Specifically, a single large scale multi-objective mixed integer programming portfolio optimization problem is constructed with a primary objective of maximizing the utility of the security measure portfolios employed in each sector of the border wall.

The paper is organized as follows. Section 5, "Systems Model Formulation" presents the CBP system resource allocation problem as a multi-objective nonlinear integer program. Section 6, "Solution Strategies," first describes a Dantzig-Wolfe decomposition approach to handle the nonlinear constraints and objective and the binding constraint of allocating resources across the sectors. It also describes a column generation approach implemented to solve the model to optimality. Section 7 "Computational Results" reports empirical results from several problem instances to demonstrate the Pareto optimal solutions and their respective trade-offs.

\section{Systems Model Formulation}

We establish here the mathematical programming model to determine the optimal allocation of security devices and measures such that we can maximize the utility of the applied portfolio, maximize the probability of detection, and minimize cost.

The parameters and decision variables used in the model are as follows:

\section{Parameters Description}

$T \quad$ The total number of border sectors

$K \quad$ Index for border sector $k=1,2, \ldots, T$

$D \quad$ Index for detection device type $d=1,2, \ldots, D$

$B_{k} \quad$ Number of apprehensions to resolve per month by sector $k$

$I_{d} \quad$ Installation cost (\$/device) associated with security measure type $d$

$C_{d} \quad$ Maximum throughput (apprehensions/month) of security measure type $d$

$E_{d k} \quad$ Number of existing devices of security measure typed at sector $k$

$K_{d k} \quad$ Capacity of the quantity of security measure type $d$ at sector $k$

$P_{d} \quad$ Conditional probability of detecting a threat given there is a threat for device type $d$

$U_{d} \quad$ Number of device type $d$ available for installation

\section{Decision Description}

Variables

$x_{d k} \quad$ Binary variable where $x_{d k}=1(0)$ if security measure type $d$ is (not) used to deter/detect apprehension station $k$

$y_{d k} \quad$ Number of security measure type $d$ to be used at sector $k$ (integer)

$s_{d k} \quad$ Number of security measure type $d$ to be installed at sector $k$ (integer)

Our constraint development begins with assigning the device types, $d$, and numbers, $x_{d k}$, of detection devices to each sector. To accomplish this, the number of devices of type $d$ to be installed at each sector, $s_{d k}$, is found by subtracting the number of devices of type $d$ currently existing from the number of devices of type $d$ used in total at each airport. Therefore, 
$y_{d k}=\left\lceil\frac{B_{k} x_{d k}}{C_{d}}\right\rceil$

(Resource Capacity Constraint)

$s_{d k}=\max \left\{y_{d k}-E_{d k}, 0\right\}, \quad$ (Device Installation Constraint)

for $d=1,2, \ldots, D$ and $k=1,2, \ldots, T$.

The sector budget constraint can be found by summing up the installation costs of each security measure at each sector, and verifying the total sum is less than or equal to the overall installation budget.

$\sum_{k=1}^{T} \sum_{d=1}^{D} I_{d} s_{d k} \leq$ Budget, $\quad$ (Sector Installation Budget Constraint)

Next, the number of new security measures installed in all sectors must be less than or equal to the total number of new devices available, and so, the device resource availability constraint becomes

$\sum_{k=1}^{T} s_{d k} \leq U_{d}, \quad$ (Resource Availability Constraint)

for device type $d=1,2, \ldots, D$.

Lastly, the sector resource capacity is defined by the number of new security measures less than or equal to the number of available billets within each sector.

$\sum_{k=1}^{T} \sum_{d=1}^{D} s_{d k} \leq K_{d k}, \quad$ (Sector Resource Constraint)

There are three objectives. The first (primary) objective is to maximize the utility of the applied portfolios. $T_{i}$ is the utility value of each sector that is equivalent to $\frac{\text { (\# Agents) } \times \text { (Border Miles) } \times(\# \text { Stations) }}{\text { (Sq Miles) }}$. This calculation is then normalized to prevent overly large objective values. The weighted, adjusted Risk Posture, covering all sectors, all countermeasures, and all risk areas is calculated as follows

Utility $=\sum_{k=1}^{T} \sum_{d=1}^{D} x_{d k} T_{k}$

The second objective is based on both the probability of a device correctly detecting a threat and the rate of apprehensions generated by each security measure. $P_{d}$ is the conditional probability that a threat is detected by security measure type $d$, given that a threat is present. $L_{k}$ is the probability that at least one of the security measures used detects the threat.

$L_{k}=1-\prod_{d=1}^{D}\left(1-x_{d k} P_{d}\right)$

Probability of Detection $=\sum_{k=1}^{T} L_{k}$

The third objective is to minimize cost. Even though there is a budget in place, the total number of dollars spent is still important. Placing a limit on the budget allows for effective yet fiscally responsible portfolios to be selected.

Cost $=\sum_{k=1}^{T} \sum_{d=1}^{D} I_{d} s_{d k}$

In summary, the three objectives are

$$
\begin{array}{ll}
z_{1}=\max & \text { Utility }=\max \sum_{k=1}^{T} \sum_{d=1}^{D} x_{d k} T_{k} \\
z_{2}=\max & \text { Probability of Detection }=\max \sum_{k=1}^{T} L_{k}=\max \quad 1-\prod_{d=1}^{D}\left(1-x_{d k} P_{d}\right)
\end{array}
$$


$z_{3}=\min \quad$ Cost $=\max \quad-1 * \sum_{k=1}^{T} \sum_{d=1}^{D} I_{d} s_{d k}$

\section{SOLUTION STRATEGIES}

The primary objective of this multi-objective problem is to maximize the utility associated with improving the security posture of the border sectors. The utility improves by adding stronger security measures to a sector that sees larger rates of apprehensions on average and having a larger region of coverage with less manpower. Each security measure has a probability of detecting a threat, with the system as a whole having an overall threat detection probability. Since the system is layered, this is a conditional probability that at least one of the measures/devices in place will detect a threat given there is a threat. From here, a system reliability analysis can be performed with the intent of maximizing risk reduction or threat detection. Since all of the security measures/devices currently in use or proposed use are independent, this is modeled as a series system.

$$
\text { Risk }=1-\left\{\begin{array}{c}
(1-P(\text { Threat disrupted by physical security measure })) \\
\times(1-P(\text { Threat disrupted by surveillance device })) \\
\times(1-P(\text { Threat disrupted by maritime assets })) \\
\times(1-P(\text { Threat disrupted by air assets })) \\
\text { etc. }
\end{array}\right.
$$

This is a mixed-integer program based on the three types of decision variables. We can reduce the number of decision variables by eliminating $y_{d k}$, which are the total number of security measures to be put in place in each sector. $y_{d k}=\left\lceil B_{k} x_{d k} / C_{d}\right\rceil$ and $y_{d k} \in \mathbb{Z}^{+}$. We can relax the integrality requirement with the following steps.

- $C_{d} y_{d k} \geq B_{k} x_{d k}(1)$

- $C_{d} y_{d k}<B_{k} x_{d k}+C_{d}(2)$

- let $y_{d k}^{\prime} \in \mathbb{R}$, then $y_{d k}^{\prime}$ satisfies both equations (1) and (2)

- Then $y_{d k}^{\prime}=\frac{B_{k} x_{d k}}{C_{d}} \forall d$ and $k$

- Now $y_{d k}$ can be obtained directly from $y_{d k}^{\prime} \leq y_{d k} \leq y_{d k}^{\prime}+1$

If $y_{d k}$ is obtained directly, then we can also determine $s_{d k}$. However, we still want to decide how many security measures to purchase and distribute so we retain the decision variables $s_{d k}$.

Even though we are considering a multi-objective approach with additional constraints, the foundation of the problem is a direct derivation of our new TSA strategic allocation model. Now that we have reduced the decision variables to $\mathrm{s}$, we can enumerate the combinations that satisfy the constraints and store them in a binary array. $X_{k}=\{x$ is feasible for sector $k\}=x_{i 1}^{k J}=\left(x_{11}^{k J}, x_{12}^{k j}, \ldots, x_{1 D}^{k j}, x_{21}^{k j}, x_{22}^{k j}, \ldots, x_{M_{k} D}^{k j}\right)$. We can then further define our $y_{d k}$ arrays as $y^{k j}=\left(y_{1}^{k j}, y_{2}^{k j}, \ldots, y_{D}^{k j}\right)$.

Define $n_{k}$ as the number of feasible solutions for sector $\mathrm{k}$. Then notice that all of the feasible solutions for sector $\mathrm{k}$ can be generated by generating all of the binary arrays for $x_{d}^{k j}$ and then computing $y_{d}^{k j}$. Next, we will define a binary variable $r_{k j}$ for each feasible solution for each sector, where $r_{k j}=1(0)$ if solution $x_{k j}$ is (not) selected to be used in sector $k$. The master problem can now be written as the following binary integer program: 
BORDER_RESOURCE_IP

Maximize

$z_{1}=\sum_{k=1}^{T} \sum_{d=1}^{D} x_{d k} T_{k}$

$z_{2}=\sum_{k=1}^{T} L_{k}=\max 1-\prod_{d=1}^{D}\left(1-x_{d k} P_{d}\right)$

$z_{3}=-1 * \sum_{k=1}^{T} \sum_{d=1}^{D} I_{d} s_{d k}$

subject to

$s_{d k} \geq y_{d k}-E_{d k}, \quad \forall d=1,2, \ldots, D, k=1,2, \ldots, T$

$\sum_{k=1}^{T} \sum_{j=1}^{n_{k}} s_{d k} r_{k j} \leq U_{d} \quad \forall d=1,2, \ldots, D$

$\sum_{k=1}^{T} \sum_{j=1}^{n_{k}} s_{d k} r_{k j} \leq K_{d k} \quad \forall d=1,2, \ldots, D, k=1,2, \ldots, T$

$r_{k j} \in\{0,1\}$

$s_{d k} \in Z^{+}$

Although the model has been decomposed, the two remaining decision variables are now being multiplied by one another in one of the objective functions as well as in multiple constraints. We will introduce a new decision variable into the model to be represented by the equation $z=s \times r$ where $s$ is a positive integer variable, and $r$ is binary. If $\mathrm{s}$ is bounded below by zero and above by any large value, $\mathrm{M}$, then we can simply add the following constraints to the model:

$z \leq M \times r$

$z \leq S$

$z \geq s-(1-r) \times M$

$z \geq 0$

We can then substitute any expressions of $s \times r$ within the model with the new integer variable $z$.

\section{COMPUTATIONAL RESULTS}

The BORDER_RESOURCE_IP ((14)-(21)) was generated in Python 3.7.3 using the gurobipy module and solved with Gurobi 8.1. The Gurobi parameters were kept at their default values, apart from turning off the pre-solve option so that Gurobi would spend less time expanding the node structure. The computational experiments were conducted on a personal computer with an AMD Ryzen 7 quad-core processor, $3.8 \mathrm{GHz}$ processor speed, and $16 \mathrm{~GB}$ of RAM. Sensitivity analysis was completed on the Georgia Institue of Technology High Throughput server cluster. Appendix A includes a summary of the data used in setting up the models. 


\section{Scenario Analysis}

We design multiple experiments to gauge the interplay and tradeoffs of the objective functions and the constraints. Herein, we report 8 scenarios to contrast the outcome.

- Model 1: Maximize Utility (Obj. 1)

- Model 2: Maximize Probability of Detection (Obj. 2)

- Model 3: Minimize Cost (based on lower bound of \$2.5 B) (Obj. 3)

- Model 4: Maximize Cost (based on upper bound of \$5 B) (Obj. 3)

- Model 5: Tri-Objective Model (Max Obj 1 \& 2, Min Obj. 3)

- Model 6: Tri-Objective Model (Max Obj 1 \& 2, Max Obj. 3)

- Model 7: Tri-Objective Model (Max Obj 1 \& 2, Min Obj. 3 with lower weight)

- Model 8: Tri-Objective Model (Max Obj 1 \& 2, Max Obj 3 with lower weight)

These scenarios allow us to observe how security measure allocations differ when different primary objectives are emphasized. We can also observe the tradeoffs - how different primary objectives impact the other objectives (positively or negatively). This allows the decision-makers to see multiple options and to consider what results remain consistent throughout the scenarios or what results change drastically depending on the focus.

Model 1 (Table 4) displays the results of maximizing the utility function (Objective 1). Maximizing the utility sees upgrading or installing a modern bollard wall in several sectors. Commercial drones, IFTs, and Imaging sensors are critical for surveillance.

TABLE 3

MODEL 1 RESULTS

\begin{tabular}{|c|c|c|c|c|c|c|c|c|c|}
\hline \multirow[b]{2}{*}{ Security Measure $\backslash$ Sector } & \multicolumn{9}{|c|}{ Maximizing Utility Function Only } \\
\hline & El Centro & San Diego & Tucson & Yuma & Big Bend & Del Rio & El Paso & Laredo & Rio Grande Valley \\
\hline New Bollard Wall (30ft) & 19 & 48 & 39 & 21 & 0 & 0 & 26 & 0 & 0 \\
\hline Pedestrian Fence (miles) (10-20 ft) & 0 & 0 & 0 & 0 & 0 & 0 & 0 & 0 & 0 \\
\hline Secondary Fence (miles) & 0 & 0 & 0 & 0 & 0 & 0 & 0 & 0 & 0 \\
\hline Tertiary Fence (miles) & 0 & 0 & 0 & 0 & 0 & 0 & 0 & 0 & 0 \\
\hline Tacical Aerostats & 0 & 0 & 0 & 0 & 3 & 1 & 0 & 2 & 2 \\
\hline Commercial Drones & 11 & 9 & 23 & 18 & 74 & 31 & 29 & 25 & 37 \\
\hline IFT & 9 & 0 & 38 & 18 & 74 & 0 & 39 & 0 & 0 \\
\hline Remote Video Surveillance System (RVSS) & 4 & 0 & 13 & 6 & 26 & 0 & 14 & 0 & 0 \\
\hline RVSS Upgrades & 4 & 0 & 13 & 6 & 26 & 0 & 14 & 0 & 0 \\
\hline Mobile Surveillance Capability (MSC) & 0 & 0 & 0 & 16 & 0 & 27 & 35 & 0 & 0 \\
\hline Agent Portable Surveillance System (APSS) & 0 & 3 & 0 & 5 & 0 & 9 & 12 & 0 & 11 \\
\hline Mobile Video Surveillance System (MVSS) & 0 & 1 & 0 & 0 & 0 & 4 & 0 & 3 & 0 \\
\hline Thermal Imaging Device (TID) & 0 & 0 & 3 & 0 & 0 & 0 & 0 & 3 & 5 \\
\hline Unattended Groud Sensors (UGS) & 5 & 4 & 15 & 8 & 33 & 0 & 18 & 11 & 16 \\
\hline Imaging Sensors (IS) & 26 & 22 & 95 & 46 & 187 & 77 & 98 & 63 & 92 \\
\hline
\end{tabular}

Model 2 (Table 4) displays the results of maximizing the probability of detection (Objective 2). Maximizing the detection capability alone provides a lesser solution due to focusing strictly on probability values. 
TABLE 4

MODEL 2 RESULTS

\begin{tabular}{|l|ccccccccc|}
\cline { 2 - 10 } \multicolumn{1}{c|}{} & \multicolumn{7}{c|}{ Maximizing Probability of Detection Only } \\
\hline \multicolumn{1}{|c}{ Security Measure| Sector } & El Centro & San Diego & Tucson & Yuma & Big Bend & Del Rio & El Paso & Laredo & Rio Grande Valley \\
\hline New Bollard Wall (30 ft) & 19 & 43 & 39 & 21 & 0 & 0 & 26 & 0 & 0 \\
Pedestrian Fence (miles) (10-20 ft) & 0 & 0 & 0 & 0 & 0 & 0 & 0 & 0 & 0 \\
Secondary Fence (miles) & 0 & 0 & 0 & 0 & 0 & 0 & 0 & 0 & 0 \\
Tertiary Fence (miles) & 0 & 0 & 0 & 0 & 0 & 0 & 0 & 0 & 0 \\
Tacical Aerostats & 0 & 0 & 0 & 0 & 3 & 0 & 0 & 2 & 2 \\
Commercial Drones & 11 & 9 & 23 & 18 & 0 & 31 & 29 & 25 & 37 \\
IFT & 11 & 0 & 0 & 0 & 0 & 0 & 39 & 0 & 0 \\
Remote Video Surveillance System (RVSS) & 4 & 0 & 13 & 6 & 26 & 0 & 0 & 0 & 0 \\
RVSS Upgrades & 4 & 0 & 13 & 0 & 26 & 0 & 14 & 0 & 0 \\
Mobile Surveillance Capability (MSC) & 0 & 0 & 0 & 16 & 0 & 27 & 35 & 0 & 0 \\
Agent Portable Surveillance System (APSS) & 0 & 3 & 0 & 5 & 0 & 9 & 12 & 0 & 11 \\
Mobile Video Surveillance System (MVSS) & 0 & 0 & 0 & 0 & 0 & 4 & 0 & 3 & 0 \\
Thermal Imaging Device (TID) & 0 & 0 & 3 & 0 & 0 & 0 & 0 & 3 & 5 \\
Unattended Groud Sensors (UGS) & 5 & 4 & 15 & 8 & 33 & 0 & 18 & 11 & 16 \\
Imaging Sensors (IS) & 0 & 22 & 0 & 0 & 0 & 0 & 0 & 0 & 0 \\
\hline
\end{tabular}

Model 3 (Table 5) reports the results of minimizing cost based on a lower bound of $\$ 2.5$ billion (Objective 3). Minimizing cost alone places slightly more emphasis on upgrading or installing new portions of the bollard wall

TABLE 5

MODEL 3 RESULTS

\begin{tabular}{|l|ccccccccc|}
\cline { 2 - 9 } \multicolumn{1}{c|}{} & \multicolumn{7}{c|}{ Minimizing Bounded Cost } \\
\hline \multicolumn{1}{|c}{ Security Measure SSector } & El Centro & San Diego & Tucson & Yuma & Big Bend & Del Rio El Paso & Laredo & Rio Grande Valley \\
\hline New Bollard Wall (30 ft) & 18 & 48 & 39 & 21 & 0 & 0 & 26 & 0 & 0 \\
Pedestrian Fence (miles) (10-20 ft) & 0 & 0 & 0 & 0 & 0 & 0 & 0 & 0 & 0 \\
Secondary Fence (miles) & 0 & 0 & 0 & 0 & 0 & 0 & 0 & 0 & 0 \\
Tertiary Fence (miles) & 0 & 0 & 0 & 0 & 0 & 0 & 0 & 0 & 0 \\
Tacical Aerostats & 0 & 1 & 0 & 0 & 3 & 1 & 0 & 2 & 1 \\
Commercial Drones & 8 & 9 & 23 & 18 & 74 & 31 & 29 & 25 & 37 \\
IFT & 11 & 0 & 0 & 18 & 32 & 0 & 0 & 0 & 0 \\
Remote Video Surveillance System (RVSS) & 4 & 0 & 0 & 0 & 26 & 0 & 0 & 0 & 0 \\
RVSS Upgrades & 4 & 0 & 0 & 6 & 26 & 0 & 14 & 0 & 0 \\
Mobile Surveillance Capability (MSC) & 0 & 0 & 0 & 16 & 0 & 26 & 0 & 0 & 0 \\
Agent Portable Surveillance System (APSS) & 0 & 0 & 0 & 0 & 0 & 0 & 11 & 0 & 11 \\
Mobile Video Surveillance System (MVSS) & 0 & 0 & 0 & 0 & 0 & 0 & 0 & 0 & 0 \\
Thermal Imaging Device (TID) & 0 & 0 & 0 & 0 & 0 & 0 & 0 & 0 & 0 \\
Unattended Groud Sensors (UGS) & 0 & 0 & 0 & 0 & 33 & 0 & 0 & 0 & 16 \\
Imaging Sensors (IS) & 0 & 0 & 0 & 0 & 0 & 0 & 98 & 46 & 0 \\
\hline
\end{tabular}


Model 4 (Table 6) displays the results of maximizing cost based on an upper bound of $\$ 5$ billion (Objective 3). Maximizing cost concentrates on remote and mobile surveillance systems versus introducing low-cost commercial drones.

TABLE 6

MODEL 4 RESULTS

\begin{tabular}{|c|c|c|c|c|c|c|c|c|c|}
\hline \multirow[b]{2}{*}{ Security Measure \Sector } & \multicolumn{9}{|c|}{ Maximizing Bounded Cost } \\
\hline & El Centro & San Diego & Tucson & Yuma & Big Bend & Del Rio & El Paso & Laredo & Rio Grande Valley \\
\hline New Bollard Wall (30 ft) & 19 & 48 & 39 & 20.99999784 & 0 & 0 & 26 & 0 & 0 \\
\hline Pedestrian Fence (miles) $(10-20 \mathrm{ft})$ & 0 & 0 & 0 & 0 & 0 & 0 & 0 & 0 & 0 \\
\hline Secondary Fence (miles) & 0 & 0 & 0 & 0 & 0 & 0 & 0 & 0 & 0 \\
\hline Tertiary Fence (miles) & 0 & 0 & 0 & 0 & 0 & 0 & 0 & 0 & 0 \\
\hline Tacical Aerostats & 0 & 1 & 0 & 0 & 3 & 1 & 0 & 2 & 2 \\
\hline Commercial Drones & 9 & 0 & 0 & 0 & 0 & 0 & 0 & 0 & 37 \\
\hline IFT & 11 & 0 & 38 & 18 & 74 & 0 & 39 & 0 & 0 \\
\hline Remote Video Surveillance System (RVSS) & 4 & 0 & 13 & 6 & 26 & 0 & 14 & 0 & 0 \\
\hline RVSS Upgrades & 4 & 0 & 13 & 6 & 26 & 0 & 14 & 0 & 0 \\
\hline Mobile Surveillance Capability (MSC) & 0 & 0 & 0 & 16 & 0 & 27 & 35 & 0 & 0 \\
\hline Agent Portable Surveillance System (APSS) & 0 & 0 & 0 & 0 & 0 & 1 & 0 & 0 & 0 \\
\hline Mobile Video Surveillance System (MVSS) & 0 & 0 & 0 & 0 & 0 & 4 & 0 & 2 & 0 \\
\hline Thermal Imaging Device (TID) & 0 & 0 & 0 & 0 & 0 & 0 & 0 & 0 & 4 \\
\hline Unattended Groud Sensors (UGS) & 0 & 0 & 0 & 0 & 0 & 0 & 0 & 2 & 0 \\
\hline Imaging Sensors (IS) & 0 & 0 & 0 & 0 & 0 & 0 & 0 & 0 & 0 \\
\hline
\end{tabular}

Model 5 (Table 7) displays the results of the full triple-objective model while minimizing objective 3, using equal weights. Multi-objective optimization, including minimal cost, concentrates resources on commercial drones, and IFTs.

TABLE 7

MODEL 5 RESULTS

\begin{tabular}{|c|c|c|c|c|c|c|c|c|c|}
\hline \multirow[b]{2}{*}{ Security Measure|Sector } & \multicolumn{9}{|c|}{ Tri-Objective Model (Min Cost) } \\
\hline & El Centro & San Diego & Tucson & Yuma & Big Bend & Del Rio & El Paso & Laredo & Rio Grande Valley \\
\hline New Bollard Wall (30 ft) & 18 & 48 & 39 & 21 & 0 & 0 & 26 & 0 & 0 \\
\hline Pedestrian Fence (miles) $(10-20 \mathrm{ft})$ & 0 & 0 & 0 & 0 & 0 & 0 & 0 & 0 & 0 \\
\hline Secondary Fence (miles) & 0 & 0 & 0 & 0 & 0 & 0 & 0 & 0 & 0 \\
\hline Tertiary Fence (miles) & 0 & 0 & 0 & 0 & 0 & 0 & 0 & 0 & 0 \\
\hline Tacical Aerostats & 0 & 1 & 0 & 0 & 3 & 1 & 0 & 2 & 1 \\
\hline Commercial Drones & 8 & 9 & 23 & 18 & 74 & 31 & 29 & 25 & 37 \\
\hline IFT & 11 & 0 & 0 & 18 & 32 & 0 & 0 & 0 & 0 \\
\hline Remote Video Surveillance System (RVSS) & 4 & 0 & 0 & 0 & 26 & 0 & 0 & 0 & 0 \\
\hline RVSS Upgrades & 4 & 0 & 0 & 6 & 26 & 0 & 14 & 0 & 0 \\
\hline Mobile Surveillance Capability (MSC) & 0 & 0 & 0 & 16 & 0 & 26 & 0 & 0 & 0 \\
\hline Agent Portable Surveillance System (APSS) & 0 & 0 & 0 & 0 & 0 & 0 & 11 & 0 & 11 \\
\hline Mobile Video Surveillance System (MVSS) & 0 & 0 & 0 & 0 & 0 & 0 & 0 & 0 & 0 \\
\hline Thermal Imaging Device (TID) & 0 & 0 & 0 & 0 & 0 & 0 & 0 & 0 & 0 \\
\hline Unattended Groud Sensors (UGS) & 0 & 0 & 0 & 0 & 33 & 0 & 0 & 0 & 16 \\
\hline Imaging Sensors (IS) & 0 & 0 & 0 & 0 & 0 & 0 & 98 & 46 & 0 \\
\hline
\end{tabular}


Model 6 (Table 8) displays the results of the full triple-objective model, maximizing 3 objectives using equal weights. Multi-objective optimization, maximizing cost, maintain focus on the IFTs, but concentrates on remote and mobile surveillance instead of small drones.

TABLE 8

MODEL 6 RESULTS

\begin{tabular}{|c|c|c|c|c|c|c|c|c|c|}
\hline \multirow[b]{2}{*}{ Security Measure\Sector } & \multicolumn{9}{|c|}{ Tri-Objective Model (Max Cost) } \\
\hline & El Centro & San Diego & Tucson & Yuma & Big Bend & Del Rio & El Paso & Laredo & Rio Grande Valley \\
\hline New Bollard Wall (30 ft) & 19 & 48 & 39 & 20.999998 & 0 & 0 & 26 & 0 & 0 \\
\hline Pedestrian Fence (miles) $(10-20 \mathrm{ft})$ & 0 & 0 & 0 & 0 & 0 & 0 & 0 & 0 & 0 \\
\hline Secondary Fence (miles) & 0 & 0 & 0 & 0 & 0 & 0 & 0 & 0 & 0 \\
\hline Tertiary Fence (miles) & 0 & 0 & 0 & 0 & 0 & 0 & 0 & 0 & 0 \\
\hline Tacical Aerostats & 0 & 1 & 0 & 0 & 3 & 1 & 0 & 2 & 2 \\
\hline Commercial Drones & 9 & 0 & 0 & 0 & 0 & 0 & 0 & 0 & 37 \\
\hline IFT & 11 & 0 & 38 & 18 & 74 & 0 & 39 & 0 & 0 \\
\hline Remote Video Surveillance System (RVSS) & 4 & 0 & 13 & 6 & 26 & 0 & 14 & 0 & 0 \\
\hline RVSS Upgrades & 4 & 0 & 13 & 6 & 26 & 0 & 14 & 0 & 0 \\
\hline Mobile Surveillance Capability (MSC) & 0 & 0 & 0 & 16 & 0 & 27 & 35 & 0 & 0 \\
\hline Agent Portable Surveillance System (APSS) & 0 & 0 & 0 & 0 & 0 & 1 & 0 & 0 & 0 \\
\hline Mobile Video Surveillance System (MVSS) & 0 & 0 & 0 & 0 & 0 & 4 & 0 & 2 & 0 \\
\hline Thermal Imaging Device (TID) & 0 & 0 & 0 & 0 & 0 & 0 & 0 & 0 & 4 \\
\hline Unattended Groud Sensors (UGS) & 0 & 0 & 0 & 0 & 0 & 0 & 0 & 2 & 0 \\
\hline Imaging Sensors (IS) & 0 & 0 & 0 & 0 & 0 & 0 & 0 & 0 & 0 \\
\hline
\end{tabular}

Model 7 (Table 9) displays the results of the full triple objective model by minimizing cost and with a lower weight. Multi-objective optimization, while minimizing cost, shows a very good distribution of technologies.

TABLE 9

MODEL 7 RESULTS

\begin{tabular}{|l|ccccccccc|}
\cline { 2 - 9 } \multicolumn{1}{c|}{} & \multicolumn{10}{c|}{ Tri-Objective Model (Min weighted Cost) } \\
\hline \multicolumn{1}{|c}{ Security Measure(Sector } & El Centro & San Diego & Tucson & Yuma & Big Bend & Del Rio & El Paso & Laredo & Rio Grande Valley \\
\hline New Bollard Wall (30 ft) & 0 & 0 & 39 & 1 & 0 & 0 & 26 & 0 & 0 \\
Pedestrian Fence (miles) (10-20 ft) & 0 & 0 & 0 & 0 & 0 & 0 & 0 & 0 & 0 \\
Secondary Fence (miles) & 0 & 0 & 0 & 0 & 0 & 0 & 0 & 0 & 0 \\
Tertiary Fence (miles) & 0 & 0 & 0 & 0 & 0 & 0 & 0 & 0 & 0 \\
Tacical Aerostats & 0 & 0 & 0 & 0 & 3 & 0 & 0 & 0 & 1 \\
Commercial Drones & 11 & 9 & 23 & 18 & 74 & 31 & 29 & 25 & 37 \\
IFT & 0 & 0 & 0 & 0 & 73 & 0 & 0 & 0 & 0 \\
Remote Video Surveillance System (RVSS) & 0 & 0 & 13 & 6 & 26 & 0 & 14 & 0 & 0 \\
RVSS Upgrades & 0 & 0 & 13 & 6 & 26 & 0 & 14 & 0 & 0 \\
Mobile Surveillance Capability (MSC) & 0 & 0 & 0 & 15 & 0 & 27 & 35 & 0 & 0 \\
Agent Portable Surveillance System (APSS) & 0 & 3 & 0 & 6 & 0 & 9 & 12 & 0 & 11 \\
Mobile Video Surveillance System (MVSS) & 0 & 0 & 0 & 0 & 0 & 4 & 0 & 3 & 0 \\
Thermal Imaging Device (TID) & 0 & 0 & 3 & 0 & 0 & 0 & 0 & 3 & 5 \\
Unattended Groud Sensors (UGS) & 5 & 4 & 15 & 9 & 33 & 0 & 18 & 11 & 16 \\
Imaging Sensors (IS) & 26 & 22 & 95 & 46 & 187 & 77 & 98 & 63 \\
\hline
\end{tabular}

Model 8 (Table 10) displays the results of the full triple objective model, by maximizing cost and with a lower weight. Multi-objective optimization, while maximizing cost, shows a very good distribution of technologies. 
TABLE 10

MODEL 8 RESULTS

\begin{tabular}{|l|ccccccccc|}
\cline { 2 - 9 } \multicolumn{1}{c|}{} & \multicolumn{10}{c|}{ Tri-Objective Model (Max weighted Cost) } \\
\hline Security Measure|Sector & El Centro & San Diego & Tucson & Yuma & Big Bend & Del Rio & El Paso & Laredo & Rio Grande Valley \\
\hline New Bollard Wall (30 ft) & 19 & 47 & 39 & 21 & 0 & 0 & 26 & 0 & 0 \\
Pedestrian Fence (miles) (10-20 ft) & 0 & 0 & 0 & 0 & 0 & 0 & 0 & 0 & 0 \\
Secondary Fence (miles) & 0 & 0 & 0 & 0 & 0 & 0 & 0 & 0 & 0 \\
Tertiary Fence (miles) & 0 & 0 & 0 & 0 & 0 & 0 & 0 & 0 & 0 \\
Tacical Aerostats & 0 & 1 & 0 & 0 & 3 & 1 & 0 & 2 & 2 \\
Commercial Drones & 11 & 9 & 23 & 18 & 74 & 31 & 29 & 25 & 37 \\
IFT & 9 & 0 & 38 & 18 & 74 & 0 & 39 & 0 & 0 \\
Remote Video Surveillance System (RVSS) & 4 & 0 & 13 & 6 & 26 & 0 & 14 & 0 & 0 \\
RVSS Upgrades & 4 & 0 & 13 & 6 & 26 & 0 & 14 & 0 & 0 \\
Mobile Surveillance Capability (MSC) & 0 & 0 & 0 & 16 & 0 & 27 & 35 & 0 & 0 \\
Agent Portable Surveillance System (APSS) & 0 & 2 & 0 & 5 & 0 & 9 & 12 & 0 & 11 \\
Mobile Video Surveillance System (MVSS) & 0 & 1 & 0 & 0 & 0 & 4 & 0 & 3 & 0 \\
Thermal Imaging Device (TID) & 0 & 0 & 3 & 0 & 0 & 0 & 0 & 3 & 5 \\
Unattended Groud Sensors (UGS) & 5 & 4 & 15 & 8 & 33 & 0 & 18 & 11 & 16 \\
Imaging Sensors (IS) & 26 & 22 & 95 & 46 & 187 & 77 & 98 & 63 \\
\hline
\end{tabular}

Models 7 and 8 both provide two very strong options in terms of optimizing multiple critical criteria while meeting different budgetary options. When only optimizing a single objective, certain security measures are left out that may be important to some missions.

Table 11 provides a consolidated model overview of how the allocation values change as we iterate through the eight models discussed above. The values in each cell represent the total units of security measures to be distributed across all sectors (sum of the rows from Tables 3-10). Although each solution presented is Pareto optimal for its specific model, each model provides a trade-off solution that might be of importance to the decision-maker. We observe how different detection measures are directly impacted by emphasizing different objectives over others or using equal weights between them. Important values to acknowledge are if concentrating on minimizing cost as in Model 7, installing new Bollard Wall along the border becomes the least important security measure to focus on while maximizing the number of commercial drones available is still a priority. In every model, it is important to install IFTs within the sectors. This is interesting due to the fact that there are hardly any IFTs operational at the moment, and they are the most expensive security measure to put into place. The model, in this case, determines that IFTs are a critical security element. Another interesting observation, if possible, it seems prudent to allocate as many drones and IFTs as possible. However, when the cost is an issue, it is important to install as many drones as possible and reduce the number of IFTs or vice versa. We see that having one or the other is critical, but having many of both is the best-case scenario. 
TABLE 11

OVERALL MODEL COMPARISON

\begin{tabular}{|c|c|c|c|c|c|c|c|c|}
\hline \multirow[b]{3}{*}{ SM|Different Model Results } & \multicolumn{8}{|c|}{ Comparison between Various Objective Models } \\
\hline & \multicolumn{8}{|c|}{ Total number of each security measure to install } \\
\hline & Model 1 & Model 2 & Model 3 & Model 4 & Model 5 & Model 6 & Model 7 & Model 8 \\
\hline New Bollard Wall (30 ft) & 153 & 148 & 152 & 153 & 152 & 153 & 66 & 152 \\
\hline Pedestrian Fence (miles) (10-20 ft) & 0 & 0 & 0 & 0 & 0 & 0 & 0 & 0 \\
\hline Secondary Fence (miles) & 0 & 0 & 0 & 0 & 0 & 0 & 0 & 0 \\
\hline Tertiary Fence (miles) & 0 & 0 & 0 & 0 & 0 & 0 & 0 & 0 \\
\hline Tacical Aerostats & 8 & 7 & 8 & 9 & 8 & 9 & 4 & 9 \\
\hline Commercial Drones & 257 & 183 & 254 & 46 & 254 & 46 & 257 & 257 \\
\hline IFT & 178 & 50 & 61 & 180 & 61 & 180 & 73 & 178 \\
\hline Remote Video Surveillance System (RVSS) & 63 & 49 & 30 & 63 & 30 & 63 & 59 & 63 \\
\hline RVSS Upgrades & 63 & 57 & 50 & 63 & 50 & 63 & 59 & 63 \\
\hline Mobile Surveillance Capability (MSC) & 78 & 78 & 42 & 78 & 42 & 78 & 77 & 78 \\
\hline Agent Portable Surveillance System (APSS) & 40 & 40 & 22 & 1 & 22 & 1 & 41 & 39 \\
\hline Mobile Video Surveillance System (MVSS) & 8 & 7 & 0 & 6 & 0 & 6 & 7 & 8 \\
\hline Thermal Imaging Device (TID) & 11 & 11 & 0 & 4 & 0 & 4 & 11 & 11 \\
\hline Unattended Groud Sensors (UGS) & 110 & 110 & 49 & 2 & 49 & 2 & 111 & 110 \\
\hline Imaging Sensors (IS) & 706 & 22 & 144 & 0 & 144 & 0 & 706 & 706 \\
\hline Total Cost per Model Plan & $\$ 4,996.66$ & $\$ 2,500.55$ & $\$ 2,500.00$ & $\$ 5,000.00$ & $\$ 2,500.00$ & $\$ 5,000.00$ & $\$ 2,502.50$ & $\$ 4,999.29$ \\
\hline
\end{tabular}

\section{Measures of Performance}

Purely comparing the three objectives (Utility, Detection, Cost), we see that Models 1, 6, and 8 are the three strongest models. The three objectives are almost the exact same and at peak points in these solutions.

TABLE 12

MEASURES OF PERFORMANCE RESULTS

\begin{tabular}{|c|c|c|c|c|c|c|c|c|}
\hline \multirow{2}{*}{ Measures of Performance } & \multicolumn{8}{|c|}{ Model } \\
\hline & 1 & 2 & 3 & 4 & 5 & 6 & 7 & 8 \\
\hline Objective 1: Utility & 2458.335 & 919.1804976 & 1143.309129 & 832.4948118 & 2291.727179 & 2457.712656 & 2292.992739 & 245.02 \\
\hline Objective 2: Detection & 8.999957 & 8.999928 & 8.986102 & 8.999588 & 8.999957 & 8.999957 & 8.999957 & 8.999957 \\
\hline Objective 3: Cost & 4996.662656 & 2500.550143 & 2500 & 5000 & 2500.258805 & 4999.716503 & 2502.495497 & 4999.29 \\
\hline
\end{tabular}

Table 13 summarizes the measures of performance when normalized between 0 and 1 . This emphasizes the equivalence among Models 1, 6, and 8. The triangle radar plot in Error! Reference source not found. displays the normalized results. What we look for in the radar plot is for the colored lines to reach as close to 1 in each corner as possible. If the model lines reach 1, then the objective has reached the maximum value amongst the various models. If a color is barely registering, then the objective value result was basically inconsequential in comparison. 
TABLE 13

NORMALIZED MODEL RESULTS

\begin{tabular}{|l|c|c|c|c|c|c|c|c|}
\hline \multirow{2}{*}{ Measures of Performance } & \multicolumn{8}{|c|}{ Normalized Model Results } \\
\cline { 2 - 10 } & Model 1 & Model 2 & Model 3 & Model 4 & Model 5 & Model 6 & Model 7 & Model 8 \\
\hline Objective 1: Utility & 1 & 0.05333789 & 0.19124471 & 0.05072685 & 0.90304958 & 1 & 0.90775159 & 1 \\
\cline { 1 - 9 } Objective 2: Detection & 1 & 0.99794377 & 0 & 0.99995897 & 1 & 1 & 0.99999997 & 1 \\
\cline { 1 - 7 } Objective 3: Cost & 0.99866506 & 0.00022006 & 0 & 1 & 0.31791367 & 1 & 0.31856118 & 1 \\
\hline
\end{tabular}

FIGURE 5

TRIANGLE RADAR PLOT SHOWS THAT MODELS 1, 6, 8 OFFER THE BEST RESOURCE PORTFOLIO

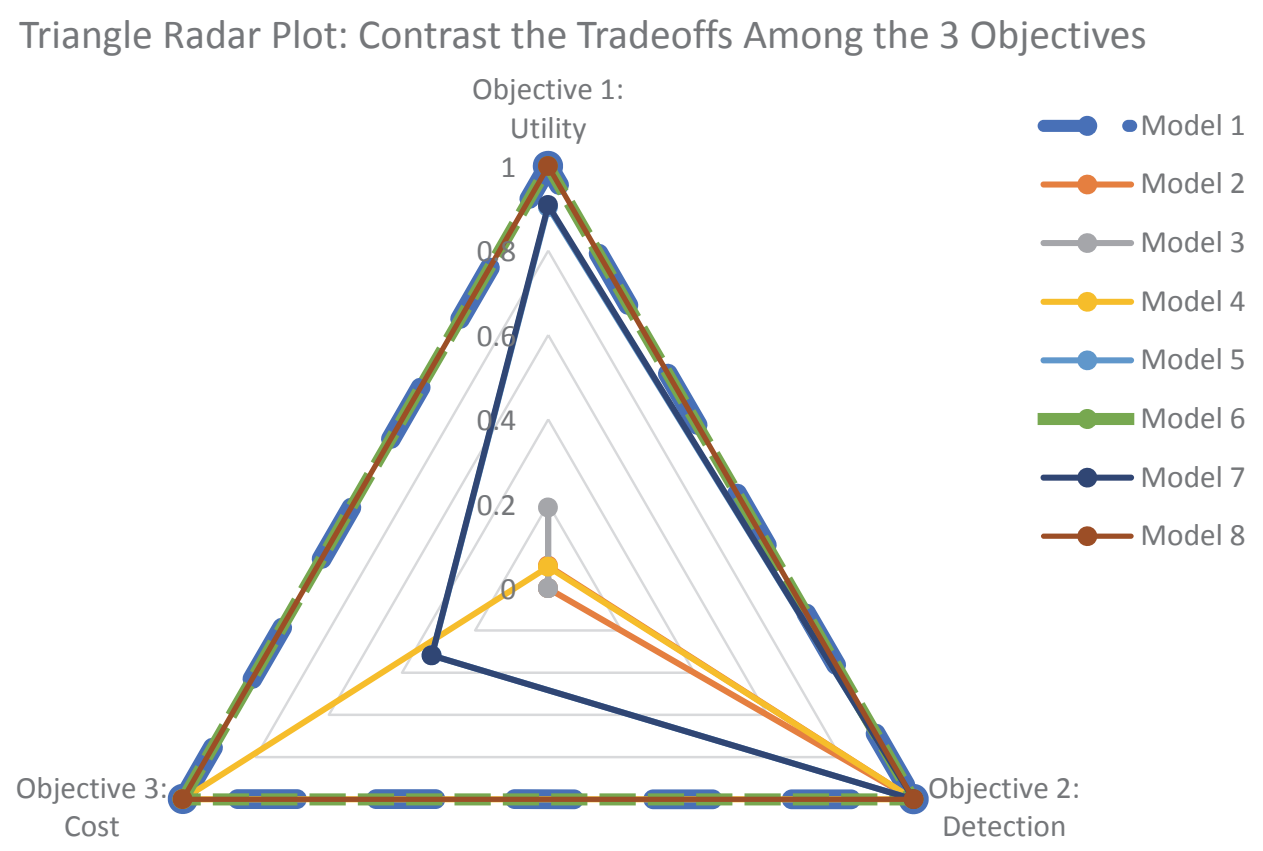

\section{Efficient Frontier}

Pareto optimality is a state of allocating resources when it is impossible to reallocate to make anyone objective improve without making at least another objective worse off. The efficient frontier represents the set of Pareto optimal portfolios that offer the highest expected return for a defined level of risk. The efficient frontier in this problem displays the tradeoff among the multiple objectives and offer a Pareto optimal solution. The decision-maker can follow the efficient frontier and select Pareto optimal alternatives that offer the same overall level of return but emphasize different levels or values of each objective. Identifying potential combinations of assets is a long researched concept originally introduced by Markowitz (Marokowitz (1952)). Typically, the objectives represented in a multi-objective portfolio optimization problem are competing. In this CBP analysis with multiple objectives that are being maximized (utility and probability of detection) versus one minimization (cost), there are several 
potentially strong alternative solutions. Any portfolios that exist along the efficient frontier have equivalent optimal values but offer up varying combinations and quantities of security measures to be allocated amongst the border sectors.

We run the multi-objective optimization instances thousands of times, varying the individual weights of the objective functions while ensuring they sum up to 1. In Figure 6 below, diagram A shows the variations in overall objective value while adjusting Objectives 1 and 2. What we would look for is for both objectives to be maximized, so we refer to the upper right corner of the graph for the Pareto portfolio combinations. Figure 6 diagram B compares Objective 1 and Objective 3, comparing maximizing utility and minimizing cost. Here we look to the bottom right-hand corner to achieve the highest utility while using the least amount of funding. For Figure 6 diagram C, we lastly compare Objectives 2 and 3, again looking to the bottom right corner for the best combinations of portfolios that achieve the highest level of detection while minimizing cost.

\section{FIGURE 6 \\ COMPARISON OF OBJECTIVE FUNCTIONS \\ (A - TOP LEFT, B - TOP RIGHT, C - BOTTOM MIDDLE)}
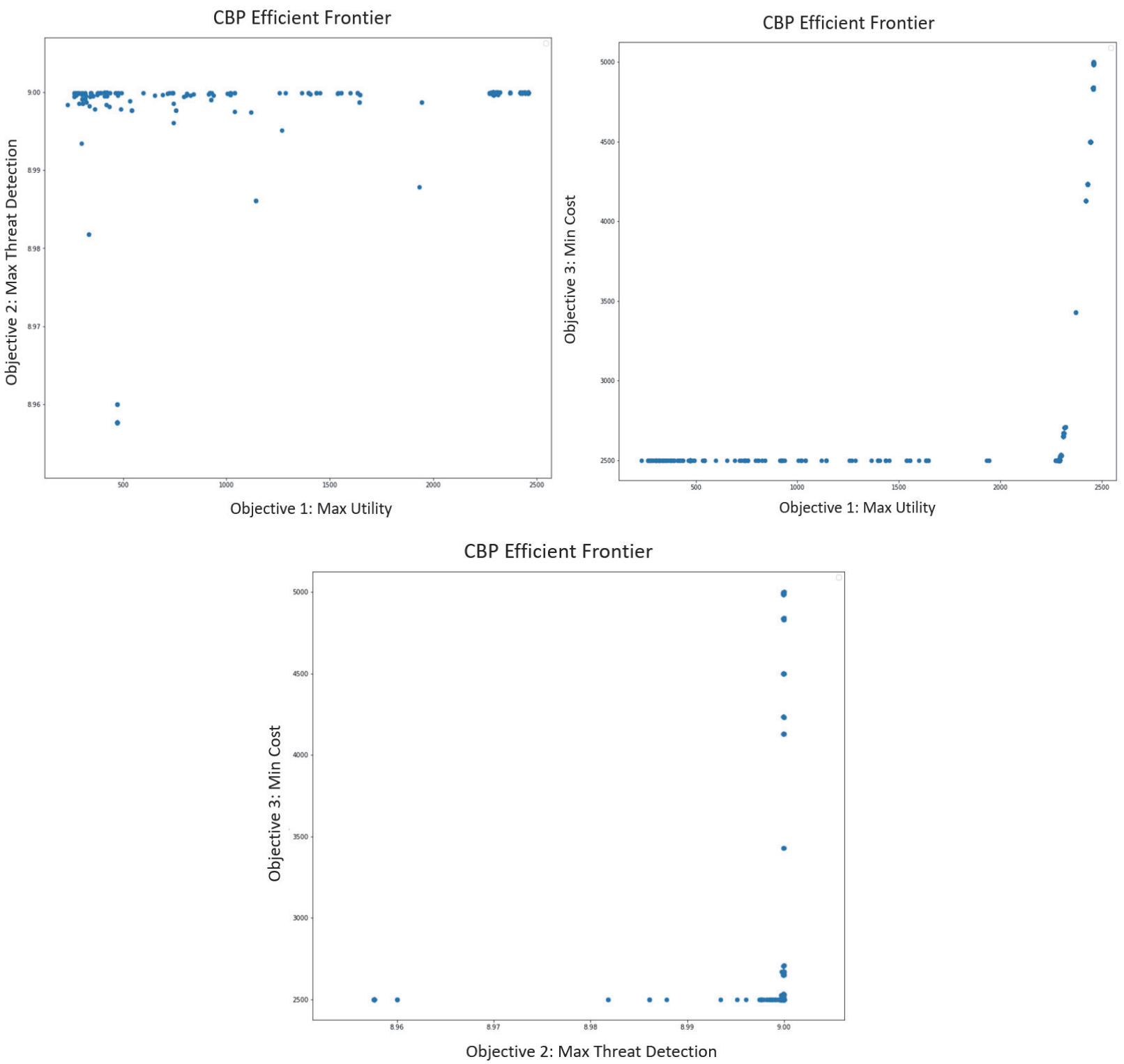
Few methods have been proposed for generating the complete Pareto efficient frontier for multiobjective optimization problems with greater than two objectives. The challenge in finding the efficient frontier comes from the number of Pareto optimal points growing with the number of objective functions. Finding a Pareto optimal point involves solving an IP, and the number of IPs to solve grows rapidly through the process. Figure 7 shows the behavior and interaction of the three fluctuating objective values together. It becomes obvious that the more funding that is available, the higher utility and threat detection capabilities are. If we reduce the budget, which is the goal, the maximum utility decreases drastically. Fortunately, the efficient frontier displays the range of possible solutions that are available for consideration to achieve acceptable good values for all three objectives simultaneously.

\section{FIGURE 7}

\section{TRIPLE OBJECTIVE SURFACE PLOT WITH EFFICIENT FRONTIER}

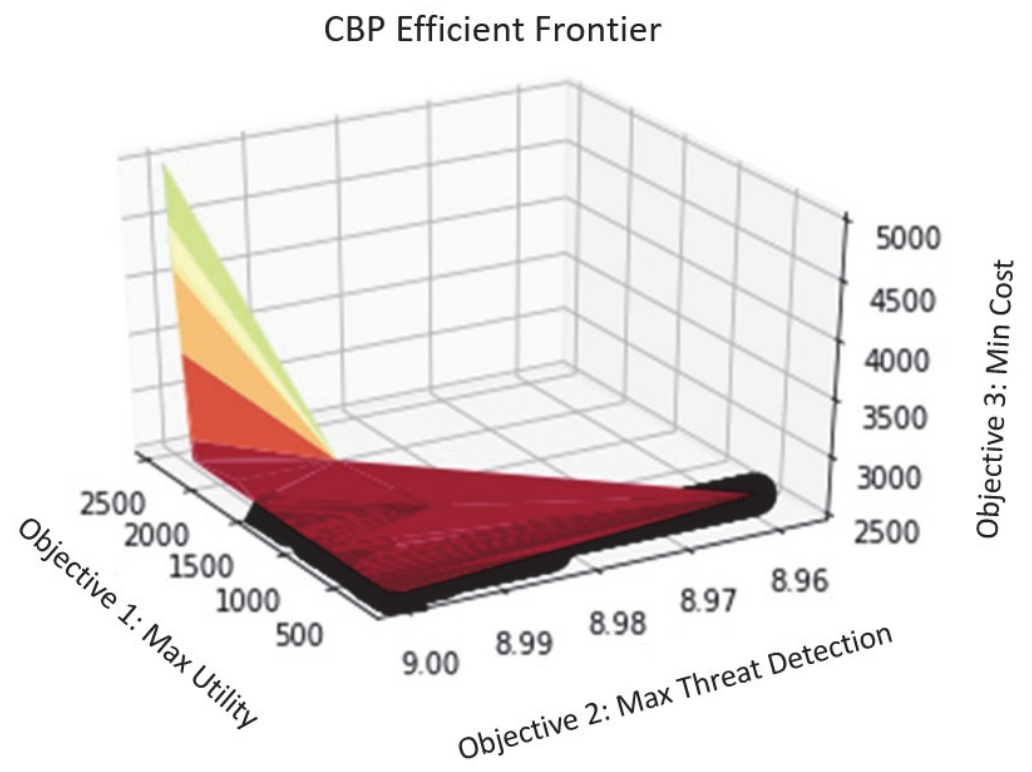

\section{CONCLUSIONS}

A large-scale multi-objective portfolio optimization integer program was successfully constructed that easily runs to optimality and provides results using Gurobi 8.1 run in Python 2.7.3. This CBP model was directly influenced by the current state-of-the-art TSA security screening research that we have designed (Leonard, Lee, Booker 2019). The overall model continues to be very flexible and can easily accommodate different resources, new constraints, and additional objectives. The solution methodologies that are being put in place are complex, current, and effective. They will allow further development of a mathematically supported decision analysis computational tool for the $\mathrm{CBP}$ to provide further justification for their capability gaps and develop smart investments.

With a strong model foundation in place, this formulation is very flexible and can easily accommodate additional and/or different objectives and constraints. Our model depends on estimates of the following input:

- False alarm detection rate for surveillance devices

- List of new and potential technologies to be considered

- Different measures of performance that can be included

- Accurate list of current devices that are employed and their locations 
Working with CBP domain experts is critical to ensure realistic data is being used for analyzing the results.

The biggest knowledge gap in the research is how well any type of optimization model concerning enterprise risk management performs at an operational level. Our TSA model is the first, which results in close to $1 / 2$ billion decision variables. This CBP model is more manageable with 13,888 integer variables (448 of those are binary) and is capable of covering a full multi-tier enterprise risk management (strategic, tactical, and operational levels). To the best of our knowledge, this is the first model to mathematically determine security strategies for the Customs and Border Patrol, as well as to introduce a utility factor to emphasize deterrence/detection impact. The model continues to be very flexible and can easily accommodate different resources, new constraints, and additional objectives.

This paper offers an application of the large-scale system we developed for TSA risk analysis and determines an optimal solution methodology for solving the security measure resource allocation model across multiple border sectors. Under physical / cyber / resource / logistics constraints, this model optimizes the allocation of limited quantities of deterrence and detection security measures across the entire southern continental U.S. border so as to maximize the total utility of the measures utilized, maximize the probability of deterrence and/or detection, and minimize cost. A utility factor is introduced to rate the impact of a security measure. The Dantzig-Wolfe decomposition approach is used to solve the nonlinear problem MIP problem instances, where optimal solutions are shown to be obtained in several seconds through several computational examples. Working with CBP, there is an opportunity to integrate a multi-tier risk taxonomy framework (Lee, Leonard, Booker 2019), e.g., incorporating migrants, cargos, materials, etc. and their risk interdependencies within the resource allocation framework problem to structure a risk-based screening strategy that makes effective use of limited screening resources. We acknowledge the paper only addresses operational and logistics challenges. Complicated human factors remain to be investigated.

\section{ACKNOWLEDGEMENT}

This material is based upon work supported by the U.S. Department of Homeland Security under Grant Award Number 17STQAC00001-01. The views and conclusions contained in this document are those of the authors and should not be interpreted as necessarily representing the official policies, either expressed or implied, of the U.S. Department of Homeland Security. 


\section{REFERENCES}

Aguilar, D. (2018, January 30). Border Security: Back to Basics with Personnel, Technology, Infrastructure. Retrieved from https://www.hstoday.us/subject-matter-areas/bordersecurity/border-security-back-basics-personnel-technology-infrastructure/

Alden, E. (2017). Is Border Enforcement Effective? What We Know and What It Means. Journal on Migration and Human Security. doi:10.14240/jmhs.v5i2.94

At border summit, CBP leaders describe strained resources. (n.d.). Retrieved from https://www.cbp.gov/newsroom/spotlights/border-summit-cbp-leaders-describe-strainedresources

Attagara, J. (2006). The Explosive Scanning Devices Allocation Problem for Airport Security Systems. $\mathrm{Ph} . \mathrm{D}$. dissertation, Texas Tech University.

Blanchfield, C., \& Kolowratnik, N. V. (n.d.). Assessing Surveillance: Infrastructures of Security in the Tohono O'odham Nation. Retrieved from https://archinect.com/features/article/150049769/assessing-surveillance-infrastructures-ofsecurity-in-the-tohono-o-odham-nation

Boland, N., Charkhgard, H., \& Savelsbergh, M. (2017). The quadrant shrinking method: A simple and efficient algorithm for solving tri-objective integer programs. European Journal of Operational Research, 260, 873-885.

Border Patrol Sectors. (n.d.). Retrieved from https://www.cbp.gov/border-security/along-usborders/border-patrol-sectors

Bristow, J. A. (2017). An Arizona border Wall Case Study.

Chukwu, W. I., Uka, P. N., \& Dike, A. O. (2014). Duality Theory in Multi Objective Linear Programming Problems. International Journal of Engineering and Science, 3.

Chambers, S. N., Boyce, G., \& Launius, S. (2019) Mortality, Surveillance and the Tertiary "Funnel Effect" on the U.S.-Mexico Border: A Geospatial Modeling of the Geography of Deterrence. Journal of Borderlands Studies (pre-print online edition). DOI: 10.1080/08865655.2019.1570861.

Committee on Homeland Security and Governmental Affairs. (2018). Border Security: Analysis of Vulnerabilities Identified by Frontline Agents.

Department of Homeland Security. (2018). DHS Border Security Metrics Report.

Harper, J. (n.d.). Going Underground: The U.S. Government's Hunt for Enemy Tunnels. Retrieved from https://www.nationaldefensemagazine.org/articles/2018/1/2/going-underground-the-usgovernments-hunt-for-enemy-tunnels

Jusionyte, I. (2018a). Called to "Ankle Alley": Tactical Infrastructure, Migrant Injuries, and Emergency Medical Services on the US-Mexico Border. American Anthropologist, 120(1), 89-101.

Lavender, M. L. (2017). Decision Model for U.S,-Mexico Border Security Measures.

Lee, E. K., Leonard, T. J., \& Booker, J. (2019). Computational Framework for Multi-tier Risk Taxonomy Modeling and Assessment. Working Paper.

Leonard, T. J., Lee, E. K., \& Booker, J. (2019). Security Measure Allocation for Optimal Aviation Security. Working Paper.

Long, D. (n.d.). CBP's Eyes in the Sky. Retrieved from https://www.cbp.gov/frontline/frontlinenovember-aerostats

Luck, S. (2018, August 21). Privacy Impact Assessment Update for the Border Surveillance Systems (BSS). DHS/CBP/PIA-022(a).

Mark, G. S., \& Kiersz, A. (2019). As the government shutdown over Trump's border wall rages, a journey along the entire 1,933-mile US-Mexico border shows the monumental task of securing it. Retrieved from https://www.businessinsider.com/us-mexico-border-wall-photos-maps-2018-5

Markowitz, H. (1952). Portfolio Selection. The Journal of Finance, 7, 77-91.

McLay, L. A. (2011). Risk-Based Resource Allocation Models for Aviation Security. In Safety and Risk Modeling and Its Applications (pp. 243-261). Springer. doi:10.1007/978-0-85729-470-8_9 
Nie, X., Batta, R., Drury, C. G., \& Lin, L. (2009). Passenger grouping with risk levels in an airport security system. European Journal of Operational Research, 194, 574-584.

Office of Immigration Statistics. (2017). Efforts by DHS to Estimate Southwest Border Security between Ports of Entry.

Office of the Inspector General. (2017). Additional Actions Needed to Better Assess Fencing's Contributions to Operations and Provide Guidance for Identifying Capability Gaps. Southwest Border Security, GAO-17-331. ${ }^{(1)}$

Office of the Inspector General. (2017). Border Patrol is Deploying Surveillance Technologies but Needs to Improve Data Quality and Assess Effectiveness. Southwest Border Security, GAO-18-119. ${ }^{(2)}$

Office of the Inspector General. (2017). CBP's Border Security Efforts - An Analysis of Southwest Border Security Between the Ports of Entry. Southwest Border Security, OIG-17-39. ${ }^{(3)}$

Patrol, U. S. (2018). Privacy Impact Assessment Update for the Border Surveillance Systems (BSS). DHS/CBP, PIA-022(A).

Reifel, C. S. (2006). Quantitative risk analysis for homeland security resource allocation. Ph.D. dissertation, Monterey California. Naval Postgraduate School.

S\&T Impact: Borders \& Ports of Entry. (n.d.). Retrieved from https://www.dhs.gov/science-andtechnology/st-impact-borders-ports-entry

Sawik, B. (2011). Multi-objective portfolio optimization by mixed integer programming. Ph.D. dissertation, AGH University of Science and Technology.

Sewell, E. C., Attagara, J., Kobza, J. E., \& Jacobson, S. H. (2012). Allocating explosive screening devices for aviation security. Journal of Transportation Security, 5, 141-155. doi:10.1007/s12198-0120087-6

Sewell, E. C., Lee, A. J., \& Jacobson, S. H. (2013). Optimal allocation of aviation security screening devices. Journal of Transportation Security, 6, 103-116. doi:10.1007/s12198-013-0106-2

U.S. Border Patrol Southwest Border Apprehensions by Sector FY2018. (n.d.). Retrieved from https://www.cbp.gov/newsroom/stats/usbp-sw-border-apprehensions

U.S. Border Patrol Southwest Border Deaths by Fiscal Year. (2019). Retrieved from https://www.cbp.gov/sites/default/files/assets/documents/2019-Mar/bp-southwest-border-sectordeaths-fy1998-fy2018.pdf

U.S. Border Patrol Total Illegal Alien Apprehensions By Fiscal Year. (2019). Retrieved from https:/www.cbp.gov/sites/default/files/assets/documents/2019-Mar/bp-total-apps-other-mexicofy2000-fy2018.pdf

U. S. Customs \& Border Protection. (2016). Cross-Border Tunnels and Border Tunnel Prevention. Fiscal Year 2015 Report to Congress. 


\section{APPENDIX}

All model parameters are based on real, publicly available data and can be retrieved and compiled from the sources below.

Immigration Apprehensions

- https://www.cbp.gov/newsroom/stats/usbp-sw-border-apprehensions

- https://www.cato.org/publications/immigration-research-policy-brief/drones-border-efficacy-privacyimplications

Border Patrol Sectors and Stations

- https://www.cbp.gov/border-security/along-us-borders/border-patrol-sectors

Existing Security Measure Parameters

- Committee on Homeland Security and Governmental Affairs. (2018). Border Security: Analysis of Vulnerabilities Identified by Frontline Agents.

- Department of Homeland Security. (2018). DHS Border Security Metrics Report.

- Long, D. (n.d.). CBP's Eyes in the Sky. Retrieved from https://www.cbp.gov/frontline/frontlinenovember-aerostats

- Office of Immigration Statistics. (2017). Efforts by DHS to Estimate Southwest Border Security between Ports of Entry.

- Office of the Inspector General. (2017). Additional Actions Needed to Better Assess Fencing's Contributions to Operations and Provide Guidance for Identifying Capability Gaps. Southwest Border Security, GAO-17-331.

- Office of the Inspector General. (2017). Border Patrol is Deploying Surveillance Technologies but Needs to Improve Data Quality and Assess Effectiveness. Southwest Border Security, GAO-18-119.

- Office of the Inspector General. (2017). CBP's Border Security Efforts - An Analysis of Southwest Border Security Between the Ports of Entry. Southwest Border Security, OIG-17-39.

- Patrol, U. S. (2018). Privacy Impact Assessment Update for the Border Surveillance Systems (BSS). DHS/CBP, PIA-022(A). 